\title{
Malignant mixed Müllerian tumor of the fallopian tube: Case report and literature review
}

\author{
ALEXANDRA LAVINIA COZLEA ${ }^{1}$, MIHAI GHEORGHE ${ }^{1}$, SZILARD LEO KISS ${ }^{1}$, ANAS FANDI ${ }^{1}$, MIHAI STANCA ${ }^{1}$, \\ SIMONA MOCAN $^{2}$, MIHAI EMIL CĂPILNA ${ }^{1}$, NICOLAE BACALBAȘA ${ }^{3}$ and ANDREEA ANAMARIA MOLDOVAN ${ }^{4}$ \\ ${ }^{1}$ First Obstetrics and Gynecology Clinic, ${ }^{2}$ Department of Pathology, 'George Emil Palade' University of Medicine, \\ Pharmacy, Science, and Technology, 540136 Târgu Mureș; ${ }^{3}$ Department of Obstetrics and Gynecology, \\ 'Carol Davila' University of Medicine and Pharmacy, 020022 Bucharest; ${ }^{4}$ Department of Infectious Diseases, \\ Brașov County Emergency Hospital, 500326 Brașov, Romania
}

Received April 19, 2021; Accepted May 19, 2021

DOI: $10.3892 /$ etm.2021.11100

\begin{abstract}
Carcinosarcoma, also known as malignant mixed Müllerian tumor (MMMT), includes both malignant epithelial and mesenchymal elements. While the endometrium is the most frequent known site for carcinosarcomas, their development in the fallopian tube is rare condition, only accounting for 0.1 to $0.5 \%$ among all gynecological malignancies. Fallopian tube MMMT is associated with an aggressive progression. A total of 94 previous case reports were reviewed and divided, after applying the exclusion criteria, into 2 groups: No evidence of disease (NED) Group including 33 patients reported to be without any residual disease at the end of the follow-up period; death of disease (DOD) Group including 51 patients who died due to the progression of fallopian carcinosarcoma or its complications. The gathered data were statistically analyzed together with a case from our clinical experience: a 65-year-old postmenopausal patient with a final histological diagnosis of fallopian carcinosarcoma staged FIGO IC2, synchronous with a serous endometrial intraepithelial carcinoma. Patient age between 41 and 60 years, symptoms at presentation and computed tomography $(\mathrm{CT}) /$ magnetic resonance imaging (MRI) tumor evidence are prognostic factors $(\mathrm{P}<0.05)$. Omentectomy [odds ratio $(\mathrm{OR})=0.3545$ ] and pelvic lymphadenectomy $(\mathrm{OR}=0.3732)$ were found to be significant factors for survival $(\mathrm{P}<0.05)$. Fimbrial localization of the tumor is a negative prognosis factor $(\mathrm{OR}=4.263)$, as well as the heterologous type of tumor $(\mathrm{OR}=2.880)$. Chemotherapy was found to improve survival $(\mathrm{OR}=0.2679)$ while radiotherapy had no influence on patient prognosis. Reporting these rare
\end{abstract}

Correspondence to: $\mathrm{Dr}$ Alexandra Lavinia Cozlea, First Obstetrics and Gynecology Clinic, 'George Emil Palade' University of Medicine, Pharmacy, Science, and Technology, 50 Gheorghe Marinescu Street, 540136 Târgu Mureș, Romania

E-mail: alexandra.cozlea@gmail.com

Key words: fallopian tube, carcinosarcoma, surgery, chemotherapy, omentectomy, lymphadenectomy cases could be essential for obtaining more precise information regarding the treatment and prognosis of patients with MMMT of the fallopian tube, in order to improve patient survival and quality of life.

\section{Introduction}

Malignant mixed Müllerian tumors (MMMT), widely known as carcinosarcomas, are extremely rare and highly malignant neoplasms when diagnosed in the female genital tract (1). Field literature recognizes the uterus, cervix and ovary as the most common primary sites of these malignancies (2). While the endometrium is the most frequent known site for carcinosarcomas, their development in the fallopian tube is a rare condition, only accounting for 0.1 to $0.5 \%$ among all gynecological malignancies $(3,4)$. Usually fallopian carcinosarcomas develop in the fifth to sixth decade in postmenopausal women, and the preoperative non-specific aspects and multiple similarities to hydrosalpinx, ovarian malignancies or tuboovarian abscess lead in most cases to a misdiagnosis. Symptomatology has no specific elements; the presenting symptom being usually abdominal pain mostly in the hypogastric area, followed by abnormal vaginal bleeding or abdominal distension, and exceptionally with an acute clinical picture $(5,6)$. Due to all the mentioned elements, a diagnosis of certitude is extremely difficult to confirm, often being verified only by the final histology result, but in some cases cervical cytology or endometrial curettage may guide the specialist (7).

Regarding the histological features, MMMTs integrate both stromal and epithelial, carcinomatous and sarcomatous elements, typically high grade, with a significantly aggressive progress and a poor patient prognosis. In addition, this type of tumor usually metastasizes and disseminates rapidly among the pelvic organs in approximately $60 \%$ of the cases, but also to the peritoneum, paraaortic lymphatic nodes, even distant metastasis to the lungs, liver or bones $(8,9)$.

The present article presents one case of fallopian MMMT with heterologous elements synchronous with an endometrial serous carcinoma surgically operated on in the First Obstetrics and Gynecology Clinic, 'George Emil Palade' University of Medicine, Pharmacy, Science, and Technology, Târgu Mureș, 
Romania. In addition, a meta-analysis of the medical literature was performed in order to find correlations between the patient medical data and prognosis.

\section{Patients and methods}

A synchronous fallopian MMMT together with an early-stage endometrial serous carcinoma is further described. Moreover, the present study incorporates all the data found in field literature regarding MMMTs, statistically analyzed in order to identify potential associations between specific characteristics and the described management of each patient and the post-treatment survival. The data available in English literature was found through Medline search, using the following keywords: 'fallopian carcinosarcoma', 'tubal carcinosarcoma' and 'fallopian malignant mixed tumor'.

During the Medline search, 94 patients were reported between 1902 and 2019. Ten cases were excluded because the patients were lost to follow-up, or because of the lack of reported information. Finally, 84 cases presented in Table I $(4,5,7,8,10-69)$, together with the one case surgically operated on by our team were included in the present analysis. The reported cases were divided into 2 groups according to patient outcome at the end of the follow-up period in each case: No Evidence of Disease (NED) group including 33 patients reported to be without any residual disease at the end of the follow-up period; death of disease (DOD) group including 51 patients who died due to the progression of fallopian carcinosarcoma or its complications. The collected data concerned the patient age at diagnosis, signs and symptoms at presentation, imaging findings, the accuracy of the first diagnosis, surgical, histological and oncological aspects.

Statistical analysis. Data were gathered from the previously reported cases in the literature and processed using Microsoft Excel. For the statistical analysis, the GraphPad InStat software (GraphPad Software, Inc.) was used, made available by 'George Emil Palade' University of Medicine, Pharmacy, Science, and Technology of Târgu Mureș, Romania. Quantitative variables were revealed as mean and median, qualitative and categorical variables being expressed as integer and percentage values. For all variable groups the normality of distribution was evaluated by applying Kolmogonov-Smirnov test. Quantitative analysis was performed using the Student's t-test for groups with Gaussian distribution of values and Mann-Whitney test for groups with abnormal distribution. Inferential statistics consisting in odds ratio (OR) calculations for mentioned pre-treatment, surgical, histopathological and oncological data was conducted with Fisher's exact test, this offering a higher accuracy. The level of statistical significance was established at a P-value of 0.05 , with a $95 \%$ confidence interval for all the investigated parameters.

\section{Case report}

Clinical and paraclinical findings. A female patient aged 65, primigravidae, primiparous presented with a moderate lower abdomen discomfort and a light atypical vaginal bleeding for 2 weeks. The patient was postmenopausal from the age of 50 , this being the first bleeding episode. At the clinical gynecologic exam, no vaginal or cervical macroscopic pathologies were detected, but abdominal palpation revealed a moderate sensitivity in the hypogastric area, accentuated in both iliac fossa. Transvaginal ultrasonography uncovered images suggesting a bilateral hydrosalpinx of $92 \times 33 \mathrm{~mm}$ on the right side and $45 \times 12 \mathrm{~mm}$ on the left side, also showing an intracavitary image pleading for a large endometrial polyp of 19x23 mm. These ultrasonography findings did not raise any suspicions or the necessity of substantial imagistic explorations, due to the absence of criteria which could indicate a neoplastic disease. After appropriate counseling and considering the patient age and associated medical conditions, the patient was scheduled for an operative hysteroscopy followed by laparoscopy and histopathological exam.

Intraoperative appearance. On October 2019, the patient was admitted to the First Obstetrics and Gynecology Clinic, Targu Mures Emergency Clinical County Hospital, Romania, for a combined hysteroscopic and laparoscopic approach. Under general anesthesia, a diagnostic hysteroscopy was performed, which revealed an atrophic endometrium with permeable tubal ostia together with an endometrial tumor suggesting a polyp. Thus, a hysteroscopic polypectomy was performed and the specimen was sent for histopathological examination.

During the laparoscopic phase, extended perianexial adhesions on the left side were found and an atrophic uterus and ovaries. Both fallopian tubes were enlarged and tumoral, similar to a hydrosalpinx with thick walls, sinuous, measuring $7 \times 2 \times 3 \mathrm{~cm}$ on the left side and $8 \times 7 \times 4 \mathrm{~cm}$ on the right side, without noticeable vegetation on the tubal surface but with mixed content, both fluid and cerebroid, expelled through the pavilion. A bilateral adnexectomy was performed and the specimen was carefully extracted through a mini laparotomy in the left iliac fossa and sent for frozen section, which confirmed malignancy. Subsequently, a laparotomy approach was chosen and a total hysterectomy, pelvic and paraaortic lymphadenectomy, appendectomy, total omentectomy were performed, without intraoperative complications and with no residual disease in the abdomen. Her postoperative recovery was uneventful under antibiotic prophylaxis and anticoagulant treatment. The patient was discharged on the 7 th postoperative day. After surgery and the final pathology result, the patient completed 6 cycles of systemic chemotherapy with carboplatin and paclitaxel and has NED.

Histopathological examination. Macroscopic and microscopic features of the two excised fallopian tubes are presented in Figs. 1 and 2. The right fallopian tube measured 110x45 mm, exhibited an increase in volume and dilated on the entire length, presenting a ruptured serosa in several portions and a friable white tumoral mass which filled and enlarged the lumen in all performed sections, with many necrotic associated with hemorrhagic areas. The left fallopian tube measured $50 \times 15 \mathrm{~mm}$, with dilated portions and the examined sections unveiling a white vegetant tumoral mass extended in the entire length of the organ.

Microscopically, in both fallopian tubes, the same type of infiltrative tumor was found, with mixed aspect: an epithelial component of high-grade serous carcinoma associated with heterologous elements, such as chondrosarcoma, liposarcoma and undifferentiated sarcoma, with 
Table I. Previously reported cases of fallopian MMMT.

\begin{tabular}{|c|c|c|c|c|c|}
\hline Patient no. & Author (Refs.) & Year of report & Age of patients (years) & FIGO stage & Outcome \\
\hline 1 & Motta (10) & 1926 & 14 & IV & DOD \\
\hline 2 & Zacho (11) & 1933 & $\mathrm{~N} / \mathrm{D}$ & IIIC & DOD \\
\hline 3 & Platz (12) & 1940 & 58 & IV & DOD \\
\hline 4 & Bochner (13) & 1961 & 58 & $\mathrm{~N} / \mathrm{D}$ & DOD \\
\hline 5 & Williams and Woodruff (14) & 1963 & 35 & IV & DOD \\
\hline 6 & Malnasy and Gaal (15) & 1963 & 45 & IIB & DOD \\
\hline 7 & McQueeney et al (16) & 1964 & 69 & IIB & DOD \\
\hline 8 & De Queiroz and Roth (17) & 1970 & 64 & IIIC & DOD \\
\hline 9 & Wu et al (18) & 1973 & 57 & IA & NED \\
\hline 10 & Acosta et al (19) & 1974 & 46 & IIB & DOD \\
\hline 11 & Acosta et al (19) & 1974 & 62 & IV & DOD \\
\hline 12 & Acosta et al (19) & 1974 & 48 & $\mathrm{IC}$ & DOD \\
\hline 13 & Aggarwal et al (20) & 1976 & 50 & IIIC & DOD \\
\hline 14 & Manes and Taylor (21) & 1976 & 76 & IA & DOD \\
\hline 15 & Manes and Taylor (21) & 1976 & 74 & IA & DOD \\
\hline 16 & Manes and Taylor (21) & 1976 & 47 & IA & NED \\
\hline 17 & Manes and Taylor (21) & 1976 & 58 & IA & NED \\
\hline 18 & Henderson et al (22) & 1977 & 62 & IIB & DOD \\
\hline 19 & Jain $(23)$ & 1977 & 52 & IA & NED \\
\hline 20 & Oka et al (24) & 1978 & 57 & IA & NED \\
\hline 21 & Hanjani et al (25) & 1980 & 62 & IV & DOD \\
\hline 22 & Viniker et al (26) & 1980 & 63 & IA & NED \\
\hline 23 & Holst and Erichsen (27) & 1981 & 65 & IIIC & NED \\
\hline 24 & O'Toole et al (28) & 1982 & 71 & IV & DOD \\
\hline 25 & Egorov (29) & 1982 & 53 & N/D & DOD \\
\hline 26 & Kahanpää et al (30) & 1983 & 65 & III & NED \\
\hline 27 & Deppe et al (31) & 1984 & 68 & IIIB & NED \\
\hline 28 & Punnonen et al (32) & 1985 & 68 & IIIC & DOD \\
\hline 29 & Buchino and Buchino (33) & 1987 & 61 & IIIC & DOD \\
\hline 30 & Yabushita et al (34) & 1987 & 53 & IIA & NED \\
\hline 31 & Chen and Wolk (35) & 1988 & 56 & $\mathrm{IC}$ & DOD \\
\hline 32 & Muntz et al (36) & 1989 & 57 & IIIC & DOD \\
\hline 33 & Muntz et al (36) & 1989 & 60 & IIIA & DOD \\
\hline 34 & Muntz et al (36) & 1989 & 61 & IV & DOD \\
\hline 35 & Axelrod et al (37) & 1989 & 62 & IIIC & NED \\
\hline 36 & Kinoshita et al (38) & 1989 & 79 & $\mathrm{IC}$ & NED \\
\hline 37 & van Dijk et al (39) & 1990 & 45 & IIA & DOD \\
\hline 38 & van Dijk et al (39) & 1990 & 67 & IIIB & DOD \\
\hline 39 & Seraj et al (40) & 1990 & 62 & IIIC & DOD \\
\hline 40 & Seraj et al (40) & 1990 & 53 & IIIC & DOD \\
\hline 41 & Liang et al (41) & 1990 & 63 & IIIC & DOD \\
\hline 42 & Chang et al (42) & 1991 & 66 & III & DOD \\
\hline 43 & Chiou et al (43) & 1991 & 63 & IIIC & DOD \\
\hline 44 & Imachi et al (5) & 1992 & 60 & IIIC & DOD \\
\hline 45 & Imachi et al (5) & 1992 & 67 & IV & DOD \\
\hline 46 & Moore et al (44) & 1992 & 66 & IIIC & DOD \\
\hline 47 & Carlson et al (45) & 1993 & 72 & IIIC & DOD \\
\hline 48 & Carlson et al (45) & 1993 & 56 & IIIC & NED \\
\hline 49 & Carlson et al (45) & 1993 & 60 & IB & NED \\
\hline 50 & Carlson et al (45) & 1993 & 44 & IA & NED \\
\hline 51 & Carlson et al (45) & 1993 & 59 & IIIB & NED \\
\hline 52 & Weber et al (46) & 1993 & 74 & IIA & NED \\
\hline
\end{tabular}


Table I. Continued.

\begin{tabular}{|c|c|c|c|c|c|}
\hline Patient no. & Author (Refs.) & Year of report & Age of patients (years) & FIGO stage & Outcome \\
\hline 53 & Zorlu et al (47) & 1994 & 38 & III & DOD \\
\hline 54 & Horn et al (48) & 1996 & 62 & IIIB & DOD \\
\hline 55 & Horn et al (48) & 1996 & 64 & IIB & DOD \\
\hline 56 & Horn et al (48) & 1996 & 69 & IIIC & DOD \\
\hline 57 & Horn et al (48) & 1996 & 71 & IV & DOD \\
\hline 58 & Ebert et al (49) & 1998 & 70 & IA & NED \\
\hline 59 & Maitra et al (50) & 2004 & 29 & IIIA & DOD \\
\hline 60 & Moustafa et al (51) & 2004 & 75 & IIA & DOD \\
\hline 61 & Humble and Carter (52) & 2004 & 63 & IIIC & DOD \\
\hline 62 & Lim et al (53) & 2004 & 57 & IA & NED \\
\hline 63 & Gagner and Mittal (54) & 2005 & 77 & IV & DOD \\
\hline 64 & Kuroda et al (55) & 2005 & 65 & IIB & DOD \\
\hline 65 & Das et al (56) & 2005 & 49 & III & NED \\
\hline 66 & Das et al (56) & 2005 & 80 & IIB & DOD \\
\hline 67 & Hudelist et al (57) & 2006 & 57 & IIB & NED \\
\hline 68 & Kuroda et al (58) & 2007 & 77 & IIIC & DOD \\
\hline 70 & Kawaguchi et al (59) & 2008 & 69 & IC & NED \\
\hline 71 & Kourea et al (60) & 2008 & 72 & IIIC & NED \\
\hline 72 & Piura et al (61) & 2009 & 46 & IIIC & NED \\
\hline 73 & Shen et al (8) & 2010 & 58 & III & DOD \\
\hline 74 & Malhotra et al (62) & 2012 & 60 & IIIC & DOD \\
\hline 75 & Watanabe et al (7) & 2012 & 53 & IIIC & NED \\
\hline 76 & Tsai et al (63) & 2012 & 57 & IIIA & NED \\
\hline 77 & Gupta and Jenison (64) & 2011 & 74 & IIIC & DOD \\
\hline 78 & Takemoto et al (65) & 2015 & 56 & IIIC & DOD \\
\hline 79 & Narin et al (66) & 2015 & 68 & IIA & NED \\
\hline 80 & Vale-Fernandes et al (67) & 2015 & 57 & IIA & NED \\
\hline 81 & Ji et al (4) & 2015 & 60 & IIIC & NED \\
\hline 82 & Monsalve et al (68) & 2015 & 71 & III & NED \\
\hline 83 & Zhang et al (1) & 2018 & 70 & IIIB & NED \\
\hline 84 & Bécsi et al (69) & 2019 & 70 & IIIB & NED \\
\hline
\end{tabular}

MMMT, malignant mixed Müllerian tumors; NED, no evidence of disease; DOD, death of disease; N/D, not determined.

extended areas of necrosis and hemorrhage. In the tubal epithelium, multiple serous intraepithelial carcinoma zones with an increased mitotic index were observed. In the right tube, the tumor was found to infiltrate the entire wall, and tumoral cells were found on the serosa. In the left tube, the tumor infiltrated only the muscular wall. The microscopic examination revealed lymphovascular emboli but without tumoral invasion in the ovaries and without metastases in all the 58 pelvic and paraaortic removed lymph nodes. The omentum and appendix were tumor-free.

Regarding the uterus, the endometrial mass appeared as a polypoid lesion with predominant atrophic glands, but with serous endometrial intraepithelial carcinoma features on the surface, with no invasion. The microscopic aspect is presented in Fig. 3. The final histological diagnosis was bilateral tubal carcinosarcoma (MMMT) and synchronous serous endometrial intraepithelial carcinoma, FIGO stage IC2 and pTNM stage pT1c2.

\section{Results}

The pre-treatment assessment of the cases previously reported in the literature $(4,5,7,8,10-69)$ is presented in Table II. The mean age was not significantly different in the study groups. Regarding the patients' repartition by decades, the age interval 41-60 years was a statistically significant protective factor towards death $(\mathrm{OR}=0.3684, \mathrm{P}=0.0419)$. Patients' age $<40$ years and 61-80 years represented a higher risk for a negative outcome, although the results were not statistically significant. Regarding the symptoms, the abdominal distention reported in the died of disease (DOD) group was confirmed to be the only one directly affecting prognosis and could be considered a risk factor for death with an $\mathrm{OR}=3.955(\mathrm{P}=0.0226)$. In addition, ascites was found to influence the outcome, being present in $17.6 \%$ of the patients included in the DOD group, but the calculated P-value for its OR was above the level of statistical significance. Tumor evidence on imaging could better 

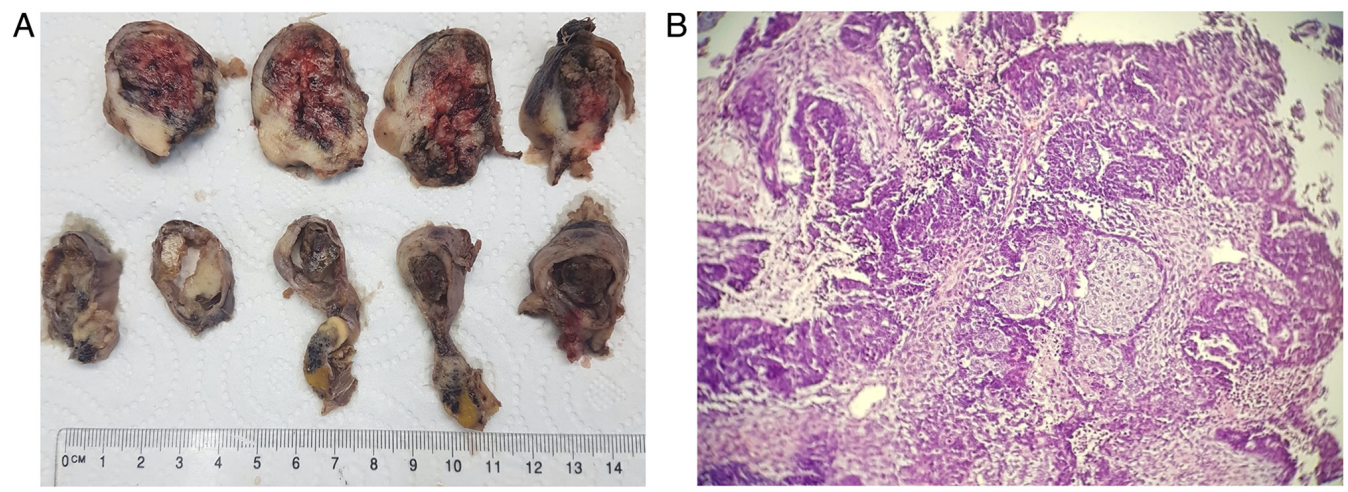

Figure 1. Right fallopian tube: (A) macroscopic and (B) microscopic features in hematoxylin and eosin staining.
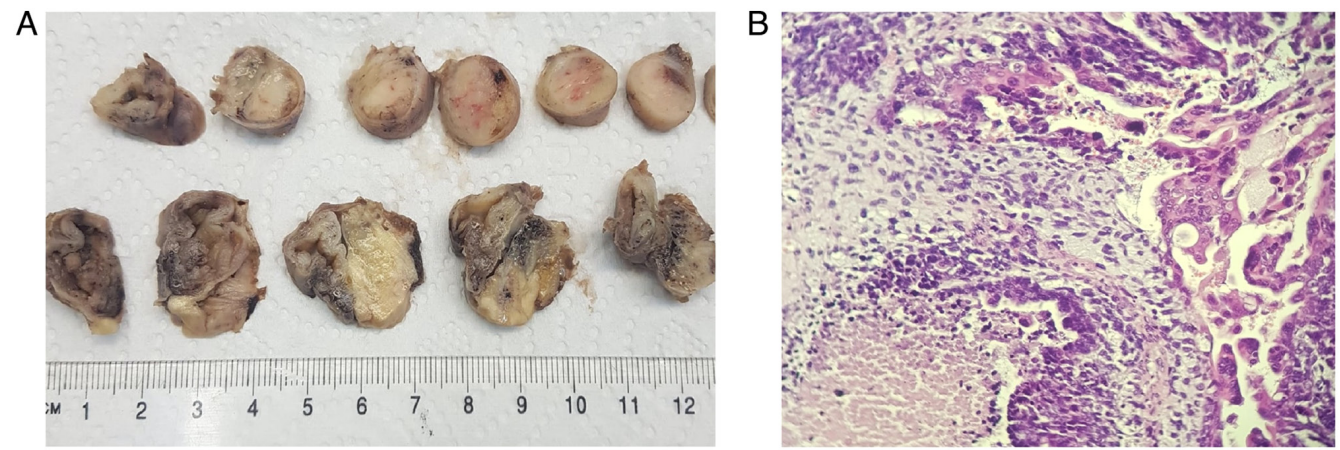

Figure 2. Left fallopian tube: (A) macroscopic and (B) microscopic features in hematoxylin and eosin staining.

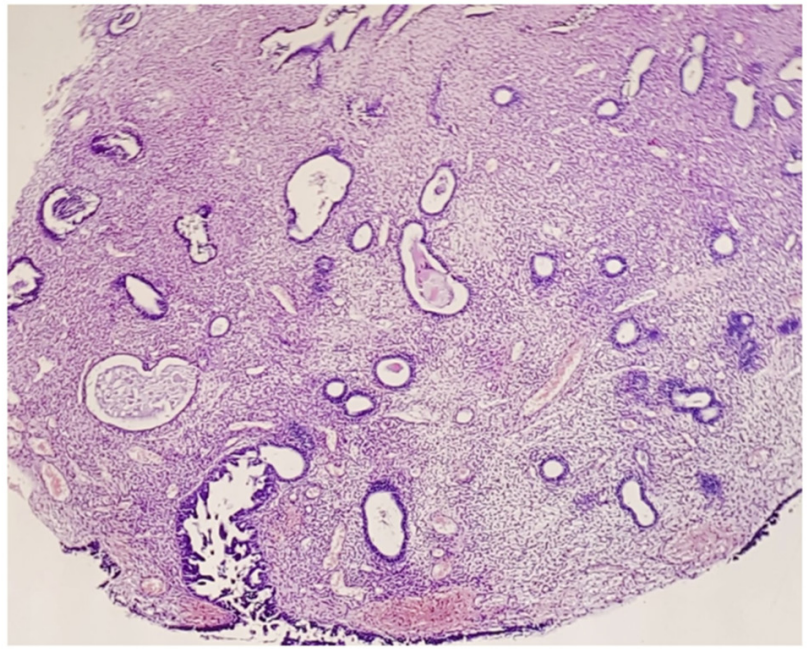

Figure 3. Endometrial polyp with 'in situ' serous carcinoma features; hematoxylin and eosin staining.

guide treatment, prolonging the life of patients $(\mathrm{OR}=0.2500$, $\mathrm{P}=0.0216$ ). Cancer antigen (CA)125 level was not shown to be a statistically significant prognostic factor, but the published data when performed by routine in patients with suspicious tubal malignancies were poor. The accuracy of the initial diagnosis was low due to the multiple non-specific elements of the disease as previously mentioned, more frequent patients being diagnosed with ovarian or pelvic tumor, followed by hydrosalpinx in both the NED and DOD groups. None of the initial misdiagnoses affected prognosis from the statistical perspective.

In Table III, the surgical management and pathology reports are shown. Concerning the surgical treatment, a total hysterectomy and bilateral salpingo-oophorectomy were performed for most of the patients. Omentectomy proved to be a statistically significant protective factor, increasing the survival ( $\mathrm{OR}=0.3545, \mathrm{P}=0.0269)$. Similar data were found regarding pelvic lymphadenectomy, performed more frequent in the NED group (42.4\%), with an $\mathrm{OR}=0.3732$ and $\mathrm{P}=0.05$. The need for bowel resection in fallopian MMMT patients could highly predispose to a poor prognosis, but the calculated chance rates $(\mathrm{OR}=7.925)$ were not statistically significant. Other surgical procedures, such as appendectomy, paraaortic lymphadenectomy, peritonectomy or metastases resection did not present statistical importance in the patient evolution.

The presence of extragenital metastases proved to be risk factors for death, especially involving the lymph nodes $(\mathrm{OR}=3.055, \mathrm{P}=0.0491)$, bowel $(\mathrm{OR}=4.263, \mathrm{P}=0.05)$ or distant organs and tissues $(\mathrm{OR}=14.976, \mathrm{P}=0.0103)$. Although omentectomy has been proven to be a protective factor, the evidence of omentum metastases was not highly reported in the reviewed articles, thus the $\mathrm{OR}$ for this parameter $(\mathrm{OR}=2.026)$ was not statistically significant. FIGO staging was another important aspect searched in previous reports. FIGO stage I can be considered a positive prognosis factor, the results fitting into protective factor intervals towards death $(\mathrm{OR}=0.1309$, $\mathrm{P}=0.0007)$. Patients with FIGO staged IIIC (OR=2.567, $\mathrm{P}=0.05)$ and IV $(\mathrm{OR}=14.976, \mathrm{P}=0.0103)$ were more susceptible to negative post-treatment outcomes. 
Table II. Pre-treatment evaluation in the field literature.

\begin{tabular}{|c|c|c|c|c|}
\hline Features & $\begin{array}{l}\text { No evidence of disease (NED) } \\
\text { group }(n=33), n(\%)\end{array}$ & $\begin{array}{l}\text { Death of disease (DOD) } \\
\text { group }(n=51), n(\%)\end{array}$ & Odds ratio $(\mathrm{OR})$ & P-value \\
\hline \multicolumn{5}{|l|}{ Age of the patients (years) } \\
\hline$<40$ & $0(0)$ & $3(5.9)$ & 4.8350 & NS \\
\hline $41-60$ & $19(57.6)$ & $17(33.3)$ & 0.3684 & 0.0419 \\
\hline $61-80$ & $14(42.4)$ & $31(60.8)$ & 2.1040 & NS \\
\hline Mean age & 60.27 & 61.25 & - & NS \\
\hline \multicolumn{5}{|l|}{ Signs and symptoms } \\
\hline Atypical vaginal bleeding & $16(48.5)$ & $21(41.2)$ & 0.7438 & NS \\
\hline Pelvic mass & $10(30.3)$ & $12(23.5)$ & 0.7077 & NS \\
\hline Abdominal pain & $13(39.4)$ & $25(49.0)$ & 1.4790 & NS \\
\hline Abdominal distention & $4(12.1)$ & $18(35.3)$ & 3.9550 & 0.0226 \\
\hline Fever & $1(3.0)$ & $2(3.9)$ & 1.3060 & NS \\
\hline Ascites & $2(6.0)$ & $9(17.6)$ & 3.3210 & NS \\
\hline \multicolumn{5}{|l|}{ Other pre-treatment findings } \\
\hline $\mathrm{CT} / \mathrm{RMN}$ tumor evidence & $10(30.3)$ & $5(9.8)$ & 0.2500 & 0.0216 \\
\hline \multicolumn{5}{|l|}{ CA125 } \\
\hline Normal & $3(9.1)$ & $1(2.0)$ & 0.2000 & NS \\
\hline Elevated (>35 U/ml) & $4(12.1)$ & $4(7.8)$ & 0.6170 & NS \\
\hline No evidence & $25(75.8)$ & $48(94.1)$ & - & - \\
\hline \multicolumn{5}{|l|}{ Accuracy of first diagnosis } \\
\hline Accurate diagnosis & $1(3.0)$ & $3(5.9)$ & 2.0000 & NS \\
\hline Ovarian tumor & $8(24.2)$ & $8(15.7)$ & 0.5814 & NS \\
\hline Pelvic tumor & $4(12.1)$ & $6(11.8)$ & 0.9667 & NS \\
\hline Hydrosalpinx & $3(9.1)$ & $1(2.0)$ & 0.2000 & NS \\
\hline Uterine tumor & $1(3.0)$ & $1(2.0)$ & 0.6400 & NS \\
\hline
\end{tabular}

CT/MRI, computed tomography/magnetic resonance imaging; CA, cancer antigen. NS, not significant $(\mathrm{P}>0.05)$. Significant $\mathrm{P}$-values $(\mathrm{P}<0.05)$ are presented in bold print.

The histologic features were also analyzed, depending on the existing evidence in the reviewed articles. Despite the lack of existing data regarding the tumor localization in different segments of the fallopian tube, an intraluminal development of the tumor could be a protective factor in relation to death $(\mathrm{OR}=0.0636)$, while fimbrial localization is more probable to be a risk factor $(\mathrm{OR}=4.263)$, but none of the parameters presented statistical significance. Analyzing the histological type of the MMMT, homologous type was a protective factor for death $(\mathrm{OR}=0.3472)$ while heterologous type could be considered a risk factor $(\mathrm{OR}=2.880)$, both parameters being extremely significant $(\mathrm{P}=0.0247)$. Due to insufficient evidence concerning the heterologous-specific elements, the obtained results are not of statistical importance.

Oncological approach and patient follow-up data are presented in Table IV. In the NED group, the majority of patients (72.7\%) received systemic chemotherapy, the statistical analysis results confirming that chemotherapy administration is a very significant protective factor against death, with an $\mathrm{OR}=0.2679$ and $\mathrm{P}=0.0070$, while the absence of chemotherapy in the treatment of fallopian MMMT is an uncontestable risk factor $(\mathrm{OR}=3.733)$. Regarding the chemotherapy agents reported, the only regimen with a statistical positive impact on the survival of patients was carboplatin + paclitaxel $(\mathrm{OR}=0.2857, \mathrm{P}=0.0293)$. The necessity of using multiple therapeutic lines during the treatment may suggest a negative outcome $(\mathrm{OR}=2.1330$, $\mathrm{OR}=2.2140$ ), but without statistical significance. Concerning radiotherapy, the evidence gathered from the literature did not suggest any significant involvement in disease progression from a statistical perspective.

Regarding the follow-up period, after eliminating the outlier values, the average was 33.40 months in the NED group and 13.19 months in the DOD group, the differences being statistically significant $(\mathrm{P}<0.0001)$. The median survival was 29 months in the NED and 8 months in the DOD group. The follow-up period depending on FIGO stage also presented several differences between the two groups. For stages I (A-C) and III (A-B), there were no statistically significant differences regarding the average follow-up period in the NED and DOD group. For FIGO stage II (A-B), the average follow-up was 29 months in the NED and 11.33 months in the DOD group, differences being statistically significant $(\mathrm{P}=0.0256)$. For stage IIIC, the average follow-up was significantly higher in the NED (31.75 months) than in the DOD group (12.13 months) $(\mathrm{P}=0.0034)$. It is also notable that were no FIGO stage IV patients in the NED group. 
Table III. Surgical management of fallopian MMMT.

\begin{tabular}{|c|c|c|c|c|}
\hline Feature & $\begin{array}{l}\text { No evidence of disease (NED) } \\
\text { group }(n=33), n(\%)\end{array}$ & $\begin{array}{l}\text { Death of disease (DOD) } \\
\text { group }(\mathrm{n}=51), \mathrm{n}(\%)\end{array}$ & $\begin{array}{l}\text { Odds } \\
\text { ratio }(\mathrm{OR})\end{array}$ & P-value \\
\hline \multicolumn{5}{|l|}{ Surgical procedure } \\
\hline Hysterectomy & $32(96.9)$ & $42(82.4)$ & 0.1458 & NS \\
\hline Bilat. salpingo-oophorectomy & $32(96.9)$ & $47(92.2)$ & 0.3672 & NS \\
\hline Omentectomy & $20(60.6)$ & $18(35.3)$ & 0.3545 & 0.0269 \\
\hline Appendectomy & $7(21.2)$ & $8(15.7)$ & 0.6910 & NS \\
\hline Pelvic lymphadenectomy & $14(42.4)$ & $11(21.6)$ & 0.3732 & 0.0500 \\
\hline Paraaortic lymphadenectomy & $6(18.2)$ & 7 (13.7) & 0.7159 & NS \\
\hline Peritonectomy & $1(3.0)$ & $2(3.9)$ & 1.3060 & NS \\
\hline Bowel resection & $0(0)$ & $5(9.8)$ & 7.9250 & NS \\
\hline Metastases resection & $5(15.2)$ & $6(11.8)$ & 0.7467 & NS \\
\hline \multicolumn{5}{|c|}{ Presence of extragenital metastases } \\
\hline Omentum & $7(21.2)$ & $18(35.3)$ & 2.0260 & NS \\
\hline Appendix & $2(6.1)$ & $2(3.9)$ & 0.6327 & NS \\
\hline Lymph nodes & $5(15.2)$ & $18(35.3)$ & 3.0550 & 0.0491 \\
\hline Peritoneum & $7(21.2)$ & $17(33.3)$ & 2.0000 & NS \\
\hline Bowel & $2(6.1)$ & $11(21.6)$ & 4.2630 & 0.0500 \\
\hline Distant & $0(0)$ & 9 (17.6) & 14.9760 & 0.0103 \\
\hline \multicolumn{5}{|l|}{ FIGO staging } \\
\hline $\mathrm{I}(\mathrm{A}-\mathrm{C})$ & $13(39.4)$ & $4(7.8)$ & 0.1309 & 0.0007 \\
\hline II (A-B) & $6(18.2)$ & $8(16.7)$ & 0.8372 & NS \\
\hline III (A-B) & $6(18.2)$ & 7 (13.7) & 0.7159 & NS \\
\hline IIIC & $8(24.2)$ & $23(45.1)$ & 2.5670 & 0.0500 \\
\hline IV & $0(0)$ & $9(17.7)$ & 14.9760 & 0.0103 \\
\hline \multicolumn{5}{|l|}{ Tumor localization } \\
\hline Intraluminal & $16(48.5)$ & $14(27.4)$ & 0.0636 & NS \\
\hline Fimbria & $2(6.1)$ & $11(21.6)$ & 4.2630 & NS \\
\hline No evidence & $15(45.4)$ & $26(51.0)$ & - & - \\
\hline \multicolumn{5}{|l|}{ Histological type } \\
\hline Homologous & $18(54.5)$ & $15(29.4)$ & 0.3472 & 0.0247 \\
\hline Heterologous & $15(45.5)$ & $36(70.6)$ & 2.8800 & 0.0247 \\
\hline Chondrosarcoma & $13(39.4)$ & $26(51.0)$ & 1.6000 & NS \\
\hline Rhabdomyosarcoma & $4(12.1)$ & $12(23.5)$ & 2.2231 & NS \\
\hline Osteosarcoma & $2(6.1)$ & $1(2)$ & 0.3100 & NS \\
\hline Liposarcoma, angiosarcoma & $4(12.1)$ & $0(0)$ & 0.0636 & 0.0212 \\
\hline
\end{tabular}

MMMT, malignant mixed Müllerian tumors; NS, not significant $(\mathrm{P}>0.05)$. Significant $\mathrm{P}$-values $(\mathrm{P}<0.05)$ are presented in bold print.

Fig. 4 presents the Kaplan-Meier survival analysis and survival rates at different checkpoints. The survival rate was 0.9879 at 1 month of follow-up, 0.8049 at 6 months, 0.4657 at 2 years, while at 5 years of follow-up it was 0.2865 .

MMMT accounts for about $2.4 \%$ of all fallopian tube malignancies, and only $4 \%$ from this histologic type develop in the fallopian tube as a primary tumor. The rarity of fallopian MMMTs could be correlated with the reduced cyclical activity and lower hormonal responsiveness of the tubal stroma, as compared with endometrial stroma where these tumors occur almost 10 times more frequently (16). These tumors are associated with high invasiveness and poor patient prognosis, especially if the diagnosis is delayed. Due to the extremely low incidence of fallopian carcinosarcoma, clinical protocols for these tumors are not clearly established $(22,70)$.

\section{Discussion}

Previously published literature reviews (Table I) $(4,5,7,8,10-69)$ have revealed that the average age of the 85 patients was 59.7 years. Regarding the symptomatology at presentation, our results are in accordance with previous reports by reporting atypical vaginal bleeding and pelvic pain or discomfort, although there is no relevant evidence for which these symptoms may be correlated with prognosis. MMMTs can present, although rarely, as acute abdomen, cases in which are associated 
Table IV. Oncological approach and follow-up.

\begin{tabular}{|c|c|c|c|c|}
\hline Treatment approach & $\begin{array}{c}\text { No evidence of } \\
\text { disease }(\text { NED) } \\
\text { group }(n=33), n(\%)\end{array}$ & $\begin{array}{c}\text { Death of } \\
\text { disease (DOD) } \\
\text { group }(n=51), n(\%)\end{array}$ & $\begin{array}{c}\text { Odds } \\
\text { ratio }(\mathrm{OR})\end{array}$ & P-value \\
\hline \multicolumn{5}{|l|}{ Chemotherapy } \\
\hline Received & $24(72.7)$ & $20(39.2)$ & 0.2679 & 0.0070 \\
\hline Not received & $9(27.3)$ & $28(54.9)$ & 3.7330 & 0.0070 \\
\hline No evidence & $0(0)$ & $3(5.9)$ & - & - \\
\hline \multicolumn{5}{|l|}{ First-line chemotherapy agents } \\
\hline Carboplatin+paclitaxel & $11(45.8)$ & $6(30.0)$ & 0.2857 & 0.0293 \\
\hline Cisplatin+doxorubicin+cyclophosphamide & $7(29.2)$ & $8(40.0)$ & 0.7429 & NS \\
\hline Cyclophosphamide+vincristine+doxorubicin & $2(8.3)$ & $1(5.0)$ & 0.3298 & NS \\
\hline Vincristine+actynomicin D+cyclophosphamide & $1(4.2)$ & $2(10.0)$ & 2.1330 & NS \\
\hline Unknown agents & $3(12.5)$ & $3(15.0)$ & - & - \\
\hline Multiple therapeutic lines & $2(8.3)$ & $6(30.0)$ & 2.2140 & NS \\
\hline \multicolumn{5}{|l|}{ Radiotherapy } \\
\hline Received & $12(36.4)$ & $16(31.4)$ & 0.8750 & NS \\
\hline Not received & $21(63.6)$ & $32(62.7)$ & 1.1430 & NS \\
\hline No evidence & $0(0)$ & $3(5.9)$ & - & - \\
\hline \multicolumn{5}{|l|}{ Follow-up (months) } \\
\hline Average & 33.40 & 13.19 & - & $<0.0001$ \\
\hline Median & 29 & 8 & & \\
\hline \multicolumn{5}{|l|}{ FIGO stage } \\
\hline Stage I (A-C) & 46.53 & 26 & - & NS \\
\hline Stage II (A-B) & 29 & 11.33 & - & 0.0256 \\
\hline Stage III (A-B) & 40.17 & 29.42 & - & NS \\
\hline Stage IIIC & 31.75 & 12.13 & - & 0.0034 \\
\hline Stage IV & - & 18.5 & - & - \\
\hline
\end{tabular}

NS, not significant $(P>0.05)$. Significant $\mathrm{P}$-values $(\mathrm{P}<0.05)$ are presented in bold print.

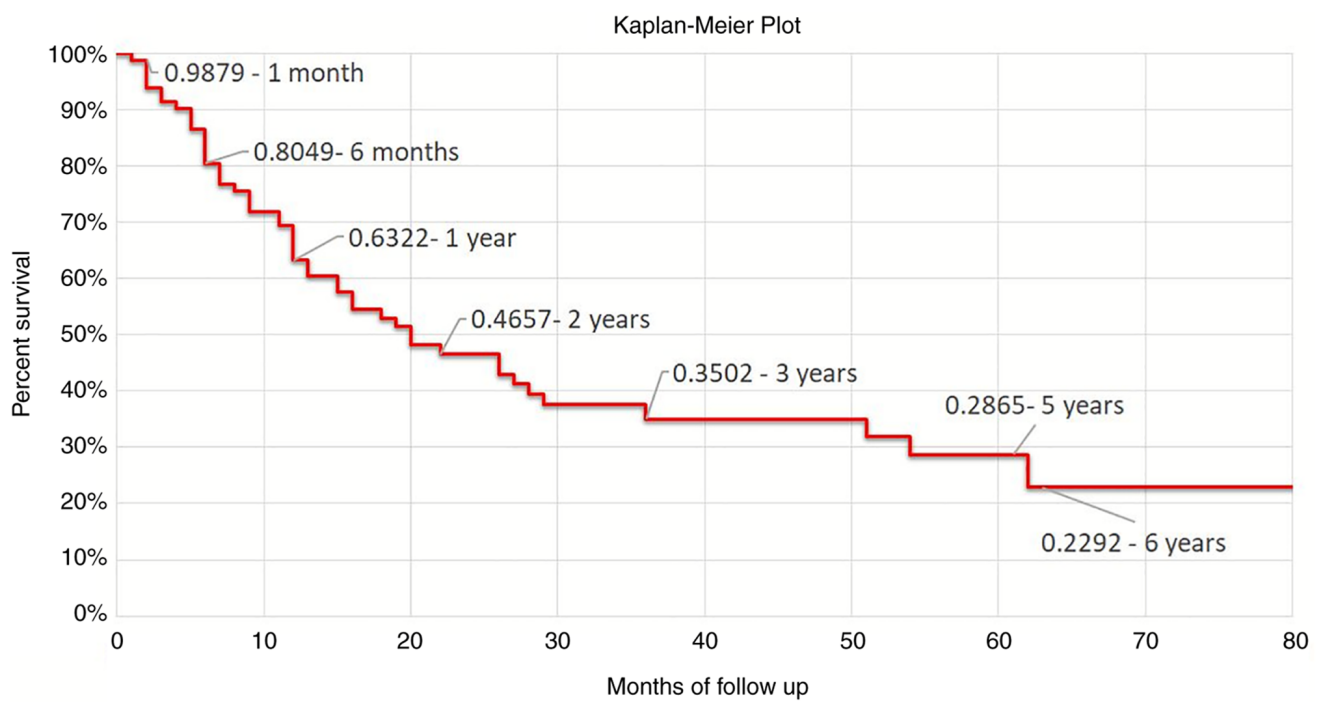

Figure 4. Kaplan-Meier survival plot at different checkpoints.

with torsion or rupture, leading to hemoperitoneum $(64,66)$.

Due to the common symptoms of MMMTs, rarity and localization, an initial definitive diagnosis is very difficult to achieve and prove, in the majority of cases remaining uncertain 
until the histological examination is performed; the most frequent preoperative and intraoperative diagnosis is related to an ovarian tumor, underlining its inaccuracy (67). Concerning imaging examination, MRI is more sensitive compared to CT to distinguish various tumor characteristics that may facilitate the preoperative diagnosis and further treatment, although imaging reports of carcinosarcoma of the fallopian tube are limited, as well as the role of CA125 (71).

Despite the lack of therapeutic protocols for fallopian MMMTs and the small number of reported cases, the strategy involves a primary surgical procedure aimed to resect all visible tumors, followed by oncological treatment intensely debated in the past decades (72). For proper staging, ascites or peritoneal washings must be collected for cytological examinations, followed by a thorough exploration of all peritoneal surfaces; a total hysterectomy and bilateral salpingo-oophorectomy must be performed, together with omentectomy, lymphadenectomy and peritoneal biopsies, depending on the intraoperative findings, achieving a maximal cytoreduction when possible $(48,73)$. As already demonstrated, omentectomy could be an important positive prognostic factor, together with pelvic lymphadenectomy, but the extent of surgery might be variable and sometimes demanding because of pelvic modified anatomy, requiring a retroperitoneal dissection (74). Regarding the possible metastatic sites, the most frequent are the contralateral tube, ovaries, uterus, but also the peritoneal surface, emphasizing that pelvic and paraaortic lymphatic nodes are not often involved, while distant metastasis is extremely rare (63), but our meta-analysis has confirmed that omentum, lymph node and distant metastases in fallopian MMMTs are often described. Sometimes, when the fallopian tumor invades other pelvic organs, different types of exenterative procedure must be performed, but these situations are rare (75).

A proper staging concerning fallopian carcinosarcomas is essential to adopt a therapeutic strategy, the survival rates being directly dependent on this parameter. As the results of the meta-analysis demonstrated, FIGO stage I presented the best survival outcomes, while FIGO stages IIIC and IV were prone to death due to disease. The prognosis of a primary fallopian tube malignancy is usually poor and depends rather on staging than on histological criteria, such as tumor type or grade (76).

Previous histological macroscopic descriptions of the tumor were similar with the present case report, revealing a dilated lumen of the tube containing polypoid or infiltrative grey or white colored mass, more frequent with necrosis and hemorrhage areas (69). Microscopically two mentioned components of the MMMT were often reported-a serous carcinoma with high-grade malignancy associated with a neoplastic proliferation of the conjunctive tissue, the presence of chondrosarcoma detected in about $50 \%$ of cases $(38,60)$. The current meta-analysis has shown that a fimbrial localization of the tumor could predispose to a more aggressive tumor evolution, an issue explained by the fact that intraluminal fluid can be discharged through the uterus in the case of fimbrial atresia. But when the end of the fimbria remains open or the tumor develops at this level, it is more likely for tumor cells to be implanted into the abdominal cavity, situations in which the prognosis is poor (77). The histological type is also known to be a prognostic factor in many gynecological malignancies.
Current meta-analysis results reporting that the heterologous type of fallopian carcinosarcoma could negatively affect survival and, by contrary, homologous MMMTs are thought to be associated with a better prognosis (78).

Systemic chemotherapy significantly improves survival, especially associated with an optimal cytoreductive surgery, as mentioned before. Over the past several decades, multiple regimens have been tried, demonstrating that adjuvant chemotherapy containing platinum agents is the most effective treatment for fallopian carcinosarcomas (79). GOG Study analyzed the association between ifosfamide and cisplatin, confirming no survival advantage, with the cost of increased toxicity (80). Currently, the combination of paclitaxel and carboplatin has been intensely studied and gained popularity in a great variety of gynecological malignant diseases, due to its important activity, acceptable toxicity and ease of administration; the results of current meta-analysis have also revealed that patients who received this drug combination exhibit better survival outcomes (59). Radiotherapy has no influence on prognosis and no benefit on survival $(25,54,57,65,81)$.

To date, the few reported fallopian MMMTs emphasize its extremely low incidence and its high malignancy, fulminant progression, and high incidence of local and distant metastases, all associated with poor survival outcomes. As an early definite diagnosis is extremely difficult to achieve even with high performance imaging examinations, most of the cases are finally diagnosed after histological evaluation. Fallopian MMMTs should be considered as a differential diagnosis in all postmenopausal patients who present with a pelvic mass, vaginal bleeding, abdominal pain or distension and with no other significant findings. Due to the non-specific presentation, symptomatology and low incidence of this neoplasia, the success of conducting large randomized trials in order to improve diagnosis accuracy, treatment options and establish international therapeutic protocols is limited. Reporting this rare pathology could be essential for obtaining more precise information regarding the diagnostic methods, targeted treatment and prognosis, in order to improve the survival and quality of life in patients with MMMTs.

\section{Acknowledgements}

Not applicable.

\section{Funding}

No funding was received to complete the present literature research.

\section{Availability of data and materials}

Data was gathered from previously published reports and collected into a database. The dataset used and analyzed during the current study is available from the corresponding author on reasonable request, all the results being included in this article.

\section{Authors' contributions}

ALC conceived, directed the project and prepared the manuscript. MEC was the leading surgeon for the surgical procedure 
described in our case report. AAM and NB supervised the work and revised the article. SM prepared and histologically analyzed the specimens. ALC, MG, SLK, AF and MS are part of the surgical team since 2016 and collected data from previously published articles. MG, SLK and MS were involved in designing and drafting the manuscript. All authors read and approved the final manuscript.

\section{Ethics approval and consent to participate}

Not applicable. Yet, informed consent was obtained for publication of the patient's data.

\section{Patient consent for publication}

The patient provided written informed consent for the scientific publication of any associated data and accompanying images.

\section{Competing interests}

Authors declare no competing interests relevant to this article.

\section{References}

1. Zhang Q, Liu A, Wu JJ, Niu M, Zhao Y, Tian SF, Chen A and Zhong L: Primary malignant mixed Müllerian tumors of the fallopian tube with cervix metastasis: A rare case report and literature review. Medicine (Baltimore) 97: e11311, 2018.

2. Lorusso D, Martinelli F, Mancini M, Sarno I, Ditto A and Raspagliesi F: Carboplatin-paclitaxel versus cisplatin-ifosfamide in the treatment of uterine carcinosarcoma: A retrospective cohort study. Int J Gynecol Cancer 24: 1256-1261, 2014.

3. Schink JC and Lurain JR: Rare gynecologic malignancies. Curr Opin Obstet Gynecol 3: 78-90, 1991.

4. Ji J, Zuo P, Li L and Wang Y: Primary malignant mixed Müllerian tumor of the fallopian tube after subtotal hysterectomy: A case report and literature review. Arch Gynecol Obstet 291: 1187-1190, 2015.

5. Imachi M, Tsukamoto N, Shigematsu T, Watanabe T, Uehira K, Amada S, Umezu T and Nakano H: Malignant mixed Müllerian tumor of the fallopian tube: Report of two cases and review of literature. Gynecol Oncol 47: 114-124, 1992.

6. Xue Q, Wu QY and Wang J: Ultrasonographic diagnosis of carcinosarcoma of the fallopian tube: A report of 1 case. Chin J Med Imaging 21: 942, 2013.

7. Watanabe T, Sugino T, Furukawa $S$, Soeda $S$, Nishiyama $H$ and Fujimori K: Malignant mixed Müllerian tumor of the fallopian tube: A case report. Eur J Gynaecol Oncol 33: 223-226, 2012.

8. Shen YM, Xie YP, Xu L, Yang KX, Yu N, Yu Y and Wang JH: Malignant mixed Müllerian tumor of the fallopian tube: Report of two cases and review of literature. Arch Gynecol Obstet 281: 1023-1028, 2010.

9. Hellström AC, Tegerstedt G, Silfverswärd C and Pettersson F: Malignant mixed Müllerian tumors of the ovary: Histopathologic and clinical review of 36 cases. Int J Gynecol Cancer 9: 312-316, 1999.

10. Motta G: Contributto alla conoscenza dei tumori misti rari dell' apperato genitale fimminile (carcinosarcoma della salpinge). Ann Obstet Ginecol 48: 611-625, 1926.

11. Zacho A: Sur le carcinoma primaire dans la trompe de fallope: Avec exposé D'un cas. Acta Obstet Gynecol Scand 13: 283-291, 1933.

12. Platz J: Über sechs weitere Fälle von primärem Tubencarcinom Arch Gynaekol 170: 604-615, 1940.

13. Bochner K: Primary uterine tube malignancy. Obstet Gynecol 18: 767-769, 1961.

14. Williams TJ and Woodruff JD: Malignant mixed mesenchymal tumor of the uterine tube: Report of a case. Obstet Gynecol 21 618-621, 1963

15. Malnasy J and Gaal M: Primary carcinosarcoma of the fallopian tube. Gynaecologia 156: 203-208, 1963.
16. McQueeney AJ, Carswell BL and Sheehan WJ: Malignant mixed Müllerian tumor primary in uterine tube: Review of the literature and report of an additional case. Obstet Gynecol 23: 338-343, 1964.

17. De Queiroz AC and Roth LM: Malignant mixed Müllerian tumor of the fallopian tube. Report of a case. Obstet Gynecol 36: 554-557, 1970.

18. Wu JP, Tanner WS and Fardal PM: Malignant mixed Müllerian tumor of the uterine tube. Obstet Gynecol 41: 707-712, 1973.

19. Acosta AA, Kaplan AL and Kaufmann RH: Mixed Müllerian tumors of the oviduct. Obstet Gynaecol 44: 84-90, 1974

20. Aggarwal S, Devi PK and Aikat M: Malignant mixed Müllerian tumour of the fallopian tube. J Obstet Gynaecol India 85: 224-236, 1976

21. Manes JL and Taylor HB: Carcinosarcoma and mixed Müllerian tumors of the fallopian tube: Report of four cases. Cancer 38: 1687-1693, 1976.

22. Henderson SR, Harper RC, Salazar OM and Rudolph JH: Primary carcinoma of the fallopian tube: Difficulties of diagnosis and treatment. Gynecol Oncol 5: 168-179, 1977.

23. Jain U: Mixed mesodermal tumor of the fallopian tube: Report of a case and review of literature. Md State Med J 26: 43-46, 1977.

24. Oka M, Bassett EP and Gross S: Malignant mixed Müllerian tumors. N Y State J Med 78: 1431-1434, 1978.

25. Hanjani P, Petersen RO and Bonnell SA: Malignant mixed Müllerian tumor of the fallopian tube. Report of a case and review of literature. Gynecol Oncol 9: 381-393, 1980.

26. Viniker DA, Mantell BS and Greenstein RJ: Carcinosarcoma of the fallopian tube: A case report and review of the literature. $\mathrm{Br} \mathrm{J}$ Obstet Gynaecol 87: 530-534, 1980.

27. Holst $\mathrm{N}$ and Erichsen A: Mixed mesodermal tumour of the fallopian tube. A case report. Ann Chir Gynaecol 70: 207-209, 1981.

28. O'Toole RV, Tuttle SE and Shah NT: Heterologous carcinosarcoma of the fallopian tube. A case report. J Reprod Med 27: 749-752, 1982.

29. Egorov VP: Heterotopic mesodermal tumor of the fallopian tube. Arkh Patol 44: 54-56, 1982 (In Russian).

30. Kahanpää KV, Laine R and Saksela E: Malignant mixed Müllerian tumor of the fallopian tube: Report of a case with 5-year survival. Gynecol Oncol 16: 144-149, 1983.

31. Deppe G, Zbella E, Friberg J and Thomas W: Combination chemotherapy for mixed Müllerian tumor of the fallopian tube. Cancer 54: 1517-1520, 1984.

32. Punnonen R, Lauslahti K and Pystynen P: Primary malignancies of the fallopian tube. Ann Chir Gynaecol Suppl 197: 15-18, 1985.

33. Buchino JJ and Buchino JJ: Malignant mixed Müllerian tumor of the fallopian tube. Arch Pathol Lab Med 111: 386-387, 1987.

34. Yabushita H, Ogawa A, Hoshina S, Okamoto T, Nakanishi M and Ishihara M: Malignant mixed mesodermal tumour of the fallopian tube. Case report. Br J Obstet Gynaecol 94: 179-183, 1987.

35. Chen KT and Wolk RW: Extragenital malignant mixed Müllerian tumor. Gynecol Oncol 30: 422-426, 1988.

36. Muntz HG, Rutgers JL, Tarraza HM and Fuller AF Jr: Carcinosarcomas and mixed Müllerian tumors of the fallopian tube. Gynecol Oncol 34: 109-115, 1989.

37. Axelrod JH, Herbold DR and Freel JH: Carcinosarcoma of the fallopian tube. Gynecol Oncol 32: 398-400, 1989.

38. Kinoshita M, Asano S, Yamashita M and Matsuda T: Mesodermal mixed tumor primary in the fallopian tube. Gynecol Oncol 32: 331-335, 1989.

39. van Dijk CM, Kooijman CD and van Lindert AC: Malignant mixed Müllerian tumour of the fallopian tube. Histopathology 16: 300-302, 1990.

40. Seraj IM, King A and Chase D: Malignant mixed Müllerian tumor of the oviduct. Gynecol Oncol 37: 296-301, 1990.

41. Liang WW, Lin YN and Lee YN: Malignant mixed Müllerian tumor of fallopian tube. Report of a case and review of literature. Zhonghua Yi Xue Za Zhi (Taipei) 45: 272-275, 1990.

42. Chang HC, Hsueh S and Soong YK: Malignant mixed Müllerian tumor of the fallopian tube. Case report and review of the literature. Changgeng Yi Xue Za Zhi 14: 259-263, 1991.

43. Chiou YK, Su IJ, Chen CA and Hsieh CY: Malignant mixed Müllerian tumor of the fallopian tube. J Formos Med Assoc 90: 793-795, 1991.

44. Moore DT, Taslimi MM and Kosanovich M: Malignant mixed Müllerian tumor of the fallopian tube of the heterologous type. J Tenn Med Assoc 85: 513-514, 1992.

45. Carlson JA Jr, Ackerman BL and Wheeler JE: Malignant mixed Müllerian tumor of the fallopian tube. Cancer 71: 187-192, 1993. 
46. Weber AM, Hewett WF, Gajewski WH and Curry SL: Malignant mixed Müllerian tumors of the fallopian tube. Gynecol Oncol 50: 239-243, 1993.

47. Zorlu CG, Cobanoglu O, Kușcu E and Aribas D: Malignant mixed Müllerian tumor of the fallopian tube. Acta Obstet Gynecol Scand 73: 352-354, 1994.

48. Horn LC, Werschnik C, Bilek K and Emmert C: Diagnosis and clinical management in malignant Müllerian tumors of the fallopian tube. A report of four cases and review of recent literature. Arch Gynecol Obstet 258: 47-53, 1996.

49. Ebert AD, Perez-Canto A, Schaller G, Entezami M, Hopp HS and Weitzel HK: Stage I primary malignant mixed Müllerian tumor of the fallopian tube. Report of a case with five-year survival after minimal surgery without adjuvant treatment. J Reprod Med 43: 598-600, 1998

50. Maitra RN, Lee J, McConnell DT, Kenwright DN and Dady P: Malignant mixed Müllerian tumour of the fallopian tube occurring in a patient with Peutz-Jegher's syndrome. Aust N Z J Obstet Gynaecol 44: 77-79, 2004.

51. Moustafa M, Beynon DW and Elmahallawy M: Primary malignant mixed Müllerian tumour of the fallopian tube. J Obstet Gynaecol 24: 940-941, 2004.

52. Humble S and Carter E: Pathologic quiz case: A right adnexal mass in a postmenopausal patient. Malignant mixed Müllerian tumor with heterologous elements arising in the fallopian tube. Arch Pathol Lab Med 128: e161-162, 2004.

53. Lim BJ, Kim JW, Yang WI and Cho NH: Malignant mixed Müllerian tumor of fallopian tube with multiple distinct heterologous components. Int J Gynecol Cancer 14: 690-693, 2004.

54. Gagner JP and Mittal K: Malignant mixed Müllerian tumor of the fimbriated end of the fallopian tube: Origin as an intraepithelial carcinoma. Gynecol Oncol 97: 219-222, 2005.

55. Kuroda N, Moriki T, Oguri H, Maeda N, Toi M, Miyazaki E, Hiroi M, Fukaya T and Enzan H: Malignant Müllerian mixed tumor (carcinosarcoma) of the fallopian tube: An immunohistochemical study of neoplastic cells. APMIS 113: 643-646, 2005

56. Das TK, Raha K, Bandyopadhyay A, Dasgupta A, Ghosh D and Mondal AK: Malignant mixed Müllerian tumour of the fallopian tube of heterologous variety-a case report. Indian J Patho Microbiol 48: 354-356, 2005

57. Hudelist G, Unterrieder K, Kandolf O, Alpi G, Pucher S, Pollak G Czerwenka K and Keckstein J: Malignant mixed Müllerian tumor with heterologous component arising in the fallopian tube-a case report. Eur J Gynaecol Oncol 27: 509-512, 2006.

58. Kuroda N, Inui Y, Ohara M, Hirouchi T, Mizuno K, Kubo A, Hayashi Y, Enzan H and Lee GH: Hyaline globule-like structures in undifferentiated sarcoma cells of malignant Müllerian mixed tumor of the fallopian tube. Med Mol Morphol 40: 46-49, 2007.

59. Kawaguchi W, Itamochi H, Kigawa J, Kanamori Y, Oishi T, Shimada M, Sato S, Sato S and Terakawa N: Chemotherapy consisting of paclitaxel and carboplatin benefits a patient with malignant mixed Müllerian tumor of the fallopian tube. Int J Clin Oncol 13: 461-463, 2008.

60. Kourea HP, Adonakis G, Androutsopoulos G,Zyli P, Kourounis G and Decavalas G: Fallopian tube malignant mixed Müllerian tumor (carcinosarcoma): A case report with immunohistochemical profiling. Eur J Gynaecol Oncol 29: 538-542, 2008.

61. Piura B, Rabinovich A, Apel-Sarid L and Shaco-Levy R: Carcinosarcoma of the fallopian tube with metastasis of its epithelial component to the ovary, appendix and omentum. J Obstet Gynaecol 29: 566-567, 2009.

62. Malhotra V, Nanda S, Chauhan MB, Marwah N and Sen R: Heterologous malignant mixed Müllerian tumor of the uterus and fallopian tube: A case report. J Gynacol Surg 28: 296-298, 2012.

63. Tsai CP, Ho ES, Ke YM, Hsu ST, Wang RC and Lu CH: Stage III malignant mixed Müllerian tumor of the fallopian tube: A case of 5-year survival after optimal debulking and adjuvant chemotherapy with paclitaxel plus carboplatin. Taiwan J Obstet Gynecol 51: 294-296, 2012.

64. Gupta R and Jenison E: A rare case of carcinosarcoma of the fallopian tube presenting with torsion, rupture and hemoperitoneum. Gynecol Oncol Case Rep 2: 4-5, 2011.

65. Takemoto Y, Ota T, Aoki Y, Ogura K, Ogishima D and Matsumoto T: Carcinosarcoma of the fallopian tube with disappearance of carcinoma cells by neoadjuvant chemotherapy: Case study. Eur J Gynaecol Oncol 36: 618-622, 2015.
66. Narin MA, Basaran D, Karalok A, Turan T and Tulunay G: Primary fallopian tube carcinosarcoma: Report of two cases. Yeditepe Med J 11: 945-948, 2015.

67. Vale-Fernandez E, Rodrigues F, Serrano P and Silva AI: Primary malignant mixed Müllerian tumour of the fallopian tube: A rare and difficult but possible diagnosis. BMJ Case Rep 2015: bcr2014209268, 2015.

68. Monsalve N, Santos M, Petrosino P, Arenas A and Sánchez Z: Tumor Mülleriano mixto heterólogo primario de trompa uterine. Rev Obstet Ginecol Venez 75: 212-216, 2015.

69. Bécsi J, Szabó B, Szabó T, Onus M, Mocan S and Căpîlna M: Malignant mixed Müllerian tumor of fallopian tube: Report of a case and review of the literature. Eur J Gynaecol Oncol 11: 143-147, 2019.

70. Mackay HJ, Buckanovich RJ, Hirte H, Correa R, Hoskins P, Biagi J, Martin LP, Fleming GF, Morgan R, Wang L, et al: A phase II study single agent of aflibercept (VEGF Trap) in patients with recurrent or metastatic gynecologic carcinosarcomas and uterine leiomyosarco. A trial of the Princess Margret Hospital, Chicago and California cancer phase II consortia. Gynecol Oncol 125: 136-140, 2012

71. Makhija S, Howden N, Edwards R, Kelley J, Townsend DW and Meltzer CC: Positron emission tomography/computed tomography imaging for the detection of recurrent ovarian and fallopian tube carcinoma: A retrospective review. Gynecol Oncol 85: 53-58, 2002.

72. Matulonis UA, Krag KJ, Krasner CN, Atkinson T, Horowitz NS, Lee $\mathrm{H}$ and Penson RT: Phase II prospective study of paclitaxel and carboplatin in older patients with newly diagnosed Müllerian tumors. Gynecol Oncol 112: 394-399, 2009.

73. Chiva L, Zanagnolo V, Querleu D, Martin-Calvo N, Arevalo-Serrano J, Căpîlna ME, Fagotti A, Kucukmetin A, Mom C, Chakalova G, et al: SUCCOR study: An international European cohort observational study comparing minimally invasive surgery versus open abdominal radical hysterectomy in patients with stage IB1 cervical cancer. Int J Gynecol Cancer 30: 1269-1277, 2020.

74. Căpîlna ME, Szabo B, Rusu SC, Becsi J, Moldovan B, Neagoe RM and Muhlfay G: Anatomical variations of the obturator veins and their surgical implications. Eur J Gynaecol Oncol 38: 263-265, 2017.

75. Căpîlna ME, Moldovan B and Szabo B: Pelvic exenteration-our initial experience in 15 cases. Eur J Gynaecol Oncol 36: 142-145, 2015.

76. Skafida E, Grammatoglou X, Katsamagkou E, Glava C, Firfiris N and Vasilakaki T: Primary malignant mixed Müllerian tumour of the fallopian tube. Report of a case. Eur J Gynaecol Oncol 31: 126-128, 2010.

77. Ma Y and Duan W: Clinical and survival analysis of 36 cases of primary fallopian tube carcinoma. World J Surg Onc 12: 311, 2014.

78. Mok JE, Kim YM, Jung MH, Kim KR, Kim DY, Kim JH, Kim YT and Nam JH: Malignant mixed Müllerian tumors of the ovary: Experience with cytoreductive surgery and platinum-based combination chemotherapy. Int J Gynecol Cancer 16: 101-105, 2006.

79. Yokoyama Y, Yokota M, Futagami M and Mizunuma H: Carcinosarcoma of the fallopian tube: Report of four cases and review of literature. Asia Pac J Clin Oncol 8: 303-311, 2012.

80. Sutton G, Brunetto VL, Kilgore L, Soper JT, McGehee R, Olt G, Lentz SS, Sorosky J and Hsiu JG: A phase III trial of ifosfamide with or without cisplatin in carcinosarcoma of the uterus: A gynecologic oncology group study. Gynecol Oncol 79: 147-153, 2000.

81. Căpîlna ME, Rusu SC, Laczko C, Szabo B and Marian C: Three synchronous primary pelvic cancers-a case report. Eur J Gynaecol Oncol 36: 216-218, 2015.

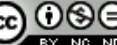

This work is licensed under a Creative Commons Attribution-NonCommercial-NoDerivatives 4.0 International (CC BY-NC-ND 4.0) License. 